\title{
ALGUMAS QUESTÕES SOBRE EDUCAÇÃO E ENSINO EM MARX E ENGELS ${ }^{1}$
}

\author{
José Claudinei Lombardi²
}

RESUMO:

Este texto delineia alguns apontamentos sobre a educação e ensino em Marx e Engels, tendo como central a categoria Modo de Produção, para a análise e compreensão da educação (e nela todo o aparato escolar). A educação, como um aspecto ou dimensão da vida social, surge e se desenvolve no interior de um modo de produção determinado, nos movimentos contraditórios que emergem do processo das lutas entre classes e frações de classe. Neste sentido, a escola moderna surge decorrente das lutas de classes, assumindo os contornos dos embates políticos passaram a se contrapor - o burguês e o proletário. Em oposição à unilateralidade da educação moderna burguesa apresenta fundamentos da proposta pedagógica comunista, na defesa da combinação entre trabalho produtivo e educação. Entre os debates, propostas e práticas pedagógicas marxistas no Brasil defende que a principal sistematização e difusão ocorre através da pedagogia histórico-crítica, sistematizada por Dermeval Saviani, principal elaborador e referência dessa concepção.

Palavras-Chave: Modo de Produção; Educação e Ensino; Marx e Engels.

\section{SOME QUESTIONS ABOUT EDUCATION AND TEACHING IN MARX AND ENGELS}

\begin{abstract}
:
This paper outlines some notes on education and teaching in Marx and Engels, whose central category Production Mode, for the analysis and understanding of education (and her entire school instruments). Education as an aspect or dimension of social life, arises and develops within a given mode of production, contradictory movements that emerge in the process of struggles between classes and class fractions. In this direction, the modern school arises due the class struggles, assuming the contours of political clashes began to oppose - the bourgeois and the proletarian. In oposition to the unilateralism of modern education bourgeois presents the fundamentals pedagogical proposal communist, in defense of the combination of productive work and education. Among the discussions, proposals and marxist pedagogical practices in Brazil argues that the key systematization and diffusion occurs through the historical-critical pedagogy, systematized by Dermeval Saviani, primary developer and reference this concept.
\end{abstract}

Keywords: Production Mode, Education and Teaching, Marx and Engels.

\section{Introdução}

A partir das pesquisas de minha tese de livre-docência, tenho publicado vários textos sobre a problemática da educação desde o marxismo originário, e acaba ficando difícil não ser repetitivo. Apesar dessa dificuldade, tentarei delinear alguns apontamentos numa direção mais geral sobre a educação e ensino em Marx e Engels. Como já explicitei, minha tese é simples, até mesmo óbvia para o marxismo: a educação (e o ensino) é determinada, em última instância, pelo modo de produção da vida material; isto é, a forma como os homens produzem sua vida material, bem como as relações aí implicadas, quais sejam, as relações de produção e as forças produtivas são fundamentais para apreender o modo como os homens vivem, pensam e transmitem as idéias e os conhecimentos que têm sobre a vida e sobre a realidade natural e social. 
No meu entendimento, para o marxismo, não faz o menor sentido analisar abstrata e ahistoricamente a educação, pois está é uma dimensão da vida dos homens que, como qualquer outro aspecto da vida e do mundo existente, se transforma historicamente, acompanhando e articulando-se às transformações do modo como os homens produzem a sua existência. A educação (e nela todo o aparato escolar) não pode ser entendida como uma dimensão estanque e separada da vida social. Como qualquer outro aspecto e dimensão da sociedade, a educação está profundamente inserida no contexto em que surge e se desenvolve, também vivenciando e expressando os movimentos contraditórios que emergem do processo das lutas entre classes e frações de classe.

Embora a afirmação se encontre em praticamente todas as analises sobre o tema, nunca é demais afirmar que Marx e Engels não se preocuparam em analisar especificamente a educação ou o ensino, e muito menos em discutir ou propor uma teoria pedagógica. As observações sobre a educação, o ensino e a qualificação profissional encontram-se esparsas no conjunto da obra, geralmente aparecem mescladas às críticas das teorizações e práticas burguesas, como a crítica da economia política e, antes dela, a da filosofia alemã e as das várias matizes do movimento socialista de então.

\section{Burguesia e proletariado: a Escola Moderna como decorrência das lutas de classe}

O entendimento da educação como um aspecto ou dimensão da vida social que surge e se desenvolve no interior de um modo de produção determinado, leva a também colocá-la nos movimentos contraditórios que emergem do processo das lutas entre classes e frações de classe.

Como as observações de Marx e Engels sobre a educação, ensino e qualificação profissional foram construídas a partir da crítica às teorizações e práticas burguesas, como foi a crítica da economia política e, antes dela, da filosofia alemã e das várias matizes de socialismo, é no contexto do modo capitalista de produção que a problemática em questão deve ser colocada.

Em trabalho anterior, dedicado ao estudo da educação implementada na rápida experiência da Comuna de Paris, entendida como um movimento revolucionário desencadeado em 1871 pelo proletariado parisiense, explicitei o caráter contraditório da implantação da educação pública na França revolucionária (LOMBARDI, 2002). Recorri à imagem do movimento do pêndulo para tentar explicitar o caráter contraditório do movimento histórico e das lutas de classes. Em se tratando da conformação e desenvolvimento da educação capitalista, esta acompanhou os vaivéns da luta entre burguesia e proletariado, assumindo as características e particularidades próprias dos processos históricos de cada uma das formações sociais articuladas na ampla teia de relações e divisões do trabalho, próprias da gênese e desenvolvimento do modo capitalista de produção.

Analisando o movimento contraditório que a educação assumiu no movimento revolucionário francês, registrei meu entendimento quanto à questão:

[...] Quando se instauram processos revolucionários, ampliando o proletariado e as frações de classes populares, participação e presença social e política, igualmente avançam as propostas pedagógicas e as formas organizadas do ensino, adquirindo um caráter público, gratuito, popular e laico; quando em seguida, reorganiza-se a burguesia e hegemoniza o poder do Estado, volta a educação a ter um caráter dual, com a defesa de uma educação pública que deve coexistir com escolas privadas nos diferentes níveis escolares, em que a gratuidade aparece como concessão do Estado aos que não podem pagar por seus estudos, etc. Essa postura da burguesia, passado o período revolucionário de formação capitalista e viabilização das condições de acumulação, desde a Revolução Francesa e a tomada do 
poder pela burguesia, passou a ser cada vez mais politicamente reacionária, mesmo quando travestida da ideologia liberal (LOMBARDI, 2002, p. 79).

É importante destacar que esse movimento contraditório entre burguesia e proletariado, bem como de suas ressonâncias na educação, é apontado não somente por marxistas, mas também por intelectuais comprometidos com um entendimento contextualizado da educação. Franco Cambi, autor de recente obra de História da Pedagogia, faz uma síntese erudita e metodologicamente eclética dos conhecimentos construídos nesse campo de investigação. Ele entende o Século XIX como aquele caracterizado pela existência de uma frontal oposição entre as duas classes fundamentais da sociedade capitalista e que se refletia em todas as dimensões da vida e organização da sociedade, seja a econômica, a social, a política e a ideológica. Cambi enfatiza o confronto entre a burguesia e o proletariado, afirmando que esse embate também produziu projetos antagônicos e radicais no que diz respeito à educação e à pedagogia (CAMBI, 1999, p. 407). Para este autor, nenhuma região do planeta ficou livre das profundas e aceleradas transformações então em curso. Conservadores, reformistas e revolucionários colocavam na educação um papel essencial, quer para manter o equilíbrio e a harmonia social, quer para promover ajustes que resolvessem disfunções sociais ou mesmo para revolucionar a ordem existente. Buscando uma síntese desse quadro e deixando claro qual o papel que o projeto de educação tem para cada classe social, assim registra em História da Pedagogia:

Numa sociedade socialmente tão lacerada [...], na qual velho e novo, tradição e revolução convivem tão íntima e dramaticamente, um papel essencial é reconhecido [...] ao compromisso educativo: para as burguesias, trata-se de perpetuar o próprio domínio técnico e sociopolítico mediante a formação de figuras profissionais capazes e impregnadas de "espírito burguês", de desejo de ordem e de espírito produtivo; para o povo, de operar uma emancipação das classes inferiores mediante a difusão da educação, isto é, mediante a libertação da mente e da consciência para chegar à libertação política. [...] Assim, também no terreno das pedagogias populares vai-se desde as reformistas até as revolucionárias..., desde as que visam a uma emancipação como integração (na sociedade burguesa) das classes populares [...] até as que reclamam, pelo contrário, uma revolução da ordem burguesa, uma tomada do poder por parte dos proletários [...] (CAMBI, 1999, p. 408-409).

Observa argutamente Cambi que, ao longo do século XIX, foram redefinidos os objetivos e os instrumentos da pedagogia. A educação assumiu os contornos dos embates políticos de então e, por volta de meados desse século, dois projetos antitéticos passaram a se contrapor - o burguês e o proletário, correspondendo a dois modelos ideológica e epistemologicamente contrapostos e inspirados, respectivamente, no positivismo e no socialismo (CAMBI, 1999, p. 465). Trata-se de duas concepções que interpretam a oposição de classe da sociedade capitalista e que articulam dois diferentes e opostos universos de valores e de organização social, inclusive no âmbito educacional.

[...] O positivismo exalta a ciência e a técnica, a ordem burguesa da sociedade e seus mitos [...], nutre-se de mentalidade laica e valoriza os saberes experimentais: é a ideologia de uma classe produtiva na época do seu triunfo, que sanciona seu domínio e fortalece sua visão do mundo. O socialismo é a posição teórica [...] da classe antagonista, que remete aos valores "negados" pela ideologia burguesa (a solidariedade e a igualdade, a participação popular no governo da sociedade) e delineia estratégias de conquista do poder que insistem sobre as contradições insanáveis da sociedade burguesa (principalmente entre capital e trabalho), delineando uma sociedade "sem classes". Também a pedagogia se caracteriza segundo 
estes dois modelos [...] (CAMBI, 1999, p. 466).

A concepção pedagógica burguesa tem sido sistematicamente tratada e defendida pela intelectualidade orgânica dessa classe. De modo geral, a exposição do conteúdo da concepção pedagógica burguesa, entre nós, tem sido analisada por Newton Duarte em uma aguda crítica ao que ele tem denominado de "pedagogias do aprender a aprender" e que expressam o amplo leque das perspectivas ideologicamente ligadas ao liberalismo e sua versão novidadeira - o neoliberalismo (DUARTE, 2000a; 2000b; 2003). Duarte inclui nesse leque o escolanovismo, o construtivismo, a pedagogia das competências, a pedagogia dos projetos, a pedagogia do professor reflexivo, etc.

Com relação ao projeto pedagógico socialista, vale lembrar que este teve início com as posições do chamado "socialismo utópico", notadamente com Fourier e Owen, confluindo para a elaboração de Marx e Engels, iniciada com a divulgação do Manifesto do Partido Comunista, em 1848. É a perspectiva educacional marxiana-engelsiana que será tratada a seguir.

\section{A centralidade da categoria Modo de Produção para o entendimento da educação e do ensino}

A partir das teorizações de Marx e Engels, a existência social passou a ser considerada como uma decorrência do próprio homem, entendido como demiurgo de sua própria história. O pressuposto primeiro de que partem, é que o homem, como um ser real precisa produzir sua própria existência, bem como garantir a produção material dos bens que tornem possível sua vida no meio natural em que vive. $\mathrm{O}$ modo de produção, portanto, foi tomado como uma categoria central para a explicação da própria existência dos homens, bem como de todas as relações que estabelecem, com a natureza e com outros homens, de suas diferentes formas de organização, de seus pensamentos e teorizações as mais diversas, como já explicitado.

O entendimento sobre o modo de produção como categoria central de análise, ênfase que dou nas disciplinas e seminários realizados na pós-graduação, acabou me levando à necessidade de aprofundamento da discussão, uma vez que tem sido relativamente comum a tônica sobre outros aspectos, tomados por pesquisadores pós-graduandos que seguem as várias escolas do pensamento marxista, tendentes a colocar ênfase sobre algumas categorias como o trabalho, o ser social, a cultura ou a própria educação. Além da interlocução gerada com algumas dissertações e teses produzidas, a primeira principal sistematização foi para os textos que escrevi para o livro Marxismo e Educação, organizado por mim e por Dermeval Saviani (LOMBARDI E SAVIANI, 2005), e mais recentemente das participações em debates promovidos pelo Grupo de Estudos e Pesquisas Marxismo, História, Tempo Livre e Educação $(\mathrm{MHTLE})^{3}$

Para melhor explicitação do conteúdo que gostaria de abordar no presente artigo, e que tomei como minha tese central, considero que o melhor encaminhamento é costurar as principais passagens d'A ideologia alemã, particularmente a primeira parte denominada "Feuerbach: oposição entre a concepção materialista e a idealista" (MARX E ENGELS, [s.d.], p. 11 e ss.], mesmo em alguns momentos repetindo analises já feitas. Já de início Marx e Engels explicitaram as premissas de que partiram, e que constituem o fundamento da materialidade ontológica e gnosiológica, expostas como segue:

As premissas de que partimos não constituem bases arbitrárias, nem dogmas; são antes bases reais de que só é possível abstrair no âmbito da imaginação. As nossas premissas são os indivíduos reais, a sua ação e as suas condições materiais de existência, quer se trate daquelas que encontrou já elaboradas quando do seu aparecimento das que ele próprio 
criou. Estas bases são portanto verificáveis por vias puramente empíricas. A primeira condição de toda a história humana é evidentemente a existência de seres humanos vivos. O primeiro estado real que encontramos é então constituído pela complexidade corporal desses indivíduos e as relações a que ela obriga com o resto da natureza. [...] Toda historiografia deve necessariamente partir dessas bases naturais e da sua modificação provocada pelos homens no decurso da história. (MARX E ENGELS, [s.d.], pp. 18-19)

Diversamente dos animais, os homens têm, antes de qualquer outra coisa, que produzir os meios necessários ao seu próprio existir. A produção de sua existência é, assim, o processo pelo qual os homens produzem sua própria vida material. O modo de produção é, portanto, a categoria que expressa a própria materialidade ontológica da história dos homens.

Pode-se referir a consciência, a religião e tudo o que se quiser como distinção entre os homens e os animais; porém, esta distinção só começa a existir quando os homens iniciam a produção dos seus meios de vida, passo em frente que é consequência da sua organização corporal. Ao produzirem os seus meios de existência, os homens produzem indiretamente a sua própria vida material.

A forma como os homens produzem esses meios depende em primeiro lugar da natureza, isto é, dos meios de existência já elaborados e que lhes é necessário reproduzir; mas não deveremos considerar esse modo de produção deste único ponto de vista, isto é, enquanto mera reprodução da existência física dos indivíduos. Pelo contrario, já constitui um modo determinado de atividade de tais indivíduos, uma forma determinada de manifestar a sua vida, um modo de vida determinado. A forma como os indivíduos manifestam a sua vida reflete muito exatamente aquilo que são. O que são coincide portanto com a sua produção, isto é, tanto com aquilo que produzem como com a forma como produzem. Aquilo que os indivíduos são depende portanto das condições materiais da sua produção." (MARX E ENGELS, [s.d.], pp. 18-19)

Assim considerado, não tenho dúvida quanto a característica fundamental e material da vida individual e social do homem: está no modo como os homens produzem sua existência . Por isso considerei o modo de produção como uma categoria fundamental, e que não deve ser considerado como "mera reprodução da existência física dos indivíduos" (Idem, ibidem). Trata-se de um modo determinado de atividade e de manifestação da vida, isto é, como um "modo de vida determinado", em que o que se produz é indissociável da forma como os homens produzem. Homens determinados, produzindo de modo determinado, estabelecendo uma teia indissociável de relações, é como Marx e Engels teceram teoricamente seu entendimento. Assim, forças produtivas, apropriação dos meios de produção, relações de produção, divisão social do trabalho, relações sociais (e estrutura social), relações políticas (e Estado), ideias ou representações (ou consciência dos homens), ideologias (como teorização invertida de um mundo invertido) são categorias que vão aparecendo teoricamente, dando complexidade contraditória ao existir social dos homens, desvelando um encadeamento sincrônico e diacrônico que se expressa como totalidade na categoria modo de produção.

Isso decorria da perspectiva onto-gnosiológica de Marx e Engels, pela qual articularam e pela qual pressupunham não a primazia da ideia, do pensamento absoluto que se auto engendra; não a centração sobre o dito, pensado, teorizado ou documentado pelos homens. É preciso, ao contrário, partir do processo de vida real, construído teoricamente (isto é, abstratamente), buscando apreender o viver dos homens, seu modo de produção, suas relações naturais e sociais, suas organizações e as instituições que as instituem, suas 
representações, suas teorizações (MARX E ENGELS, [s.d.], p. 26). Marx e Engels, porém, não tomaram a categoria modo de produção como uma categoria geral e abstrata, idealizadora e mistificadora, a-histórica, mecânica ou determinista. Por se tratar de uma articulação teórica de premissas onto-gnosiológicas, fundadas num homem que, cotidiana e historicamente, têm que produzir e reproduzir as condições necessárias à sua existência física, social e espiritual, a concepção resultante tem que apreender o processo de desenvolvimento real dos homens, realizados sob condições historicamente determinadas.

Esta forma de considerar o assunto não é desprovida de pressupostos. Parte de premissas reais e não as abandona um único instante. Estas premissas são os homens, não isolados nem fixos de uma forma imaginária qualquer, mas apreendidos no seu processo de desenvolvimento real em condições determinadas, desenvolvimento este que é visível empiricamente. Desde que se represente este processo de atividade vital, a história deixa de ser uma coleção de fatos sem vida, como a apresentam os empiristas, e que são ainda abstratos, ou a ação imaginária de sujeitos imaginários, como a apresentam os idealistas.

É onde termina a especulação, isto é, na vida real, que começa a ciência, positiva, a expressão da atividade prática, do processo de desenvolvimento prático dos homens. É nesse ponto que termina o fraseado oco sobre a consciência e o saber real passa a ocupar o seu lugar. Ao expor a realidade, a filosofia deixa de ter um meio onde possa existir de forma autônoma. (MARX E ENGELS, [s.d.], pp.26-27)

Uma vez feita a aguda crítica às formulações idealistas, a partir da crítica à Hegel e à Escola Hegeliana, a crítica à Feuerbach e seu materialismo fenomênico e a-histórico, afirmaram que era fundamental a construção de uma perspectiva ao mesmo tempo materialista, dialética e histórica.

[...] Para Feuerbach, a "concepção" do mundo sensível limita-se, por um lado, à simples contemplação deste ultimo e, por outro, ao simples sentimento. Refere-se ao "Homem em vez de se referir aos "homens históricos reais. "O homem" é na realidade "o alemão". [...] Para eliminar estes objetos é-lhe necessário refugiar-se num duplo ponto de vista: entre uma visão profana que apenas se apercebe daquilo "que é visível a olho nu" e uma outra mais elevada, filosófica, que alcança a "verdadeira essência das coisas". Não vê que o mundo sensível em seu redor não é objeto dado diretamente para toda a eternidade, e sempre igual a si mesmo, mas antes o produto da indústria e do estado da sociedade, isto é, um produto histórico, o resultado da atividade de toda uma série de gerações cada uma das quais ultrapassava a precedente, aperfeiçoando a sua indústria e o seu comércio, e modificava o seu regime social em função da modificação das necessidades. [...] (MARX E ENGELS, [s.d.], pp. 29-30)

Enquanto materialista, Feuerbach nunca faz intervir a história; e quando aceita a história, não é materialista. Nele, historia e materialismo são coisas completamente separadas, o que de resto já é suficientemente explicado pelas considerações precedentes. (Idem, p. 33)

Marx retomou de modo sistemático a discussão sobre modo de produção no Prefácio à Crítica da Economia Política, em grande medida retomando sinteticamente a discussão feita em A ideologia alemã. Também os fundamentos dessa visão histórica, com a expressão teórica que deram a ela, foi objeto de análise de Marx e Engels em várias de suas outras obras. O simples arrolamento dos títulos de algumas dessas obras já constituem estímulo para a 
continuidade dos estudos e aprofundamento do tema: Formações econômicas pré-capitalistas (Marx); Origem da Família, da propriedade privada e do Estado (Engels); Sobre o papel do trabalho na transformação do maçado em Homem (Engels); e principalmente a gigantesca e magna obra de Marx, $O$ Capital.

A partir desse entendimento sobre a categoria modo de produção, é que avancei para o entendimento marxiano e engelsiano sobre a educação. Sobre isso penso que já escrevi muito, desde o livro Marxismo e educação, organizado por mim e Dermeval Saviani (LOMBARDI E SAVIANI, 2005). Tenho sido enfático em afirmar que, nos dias atuais, bem cabem as críticas de Marx e Engels às perspectivas que tratam a educação contemporaneamente, quais sejam: como uma ideia que paira sobre nossas cabeças, iluminando nossos destinos; como uma expressão de pensamentos e ideias de sujeitos mais ou menos ilustres e que marcam toda a educação de uma época; como discurso articulado e passível de conhecimento; como memória; como fenômeno empiricamente observável, etc. Ao contrário dessas abordagens, as observações já elencadas de Marx e Engels com relação às tradições filosóficas alemãs, objeto da ácida e satírica crítica que produziram como "acerto de contas" com a trajetória anterior, permitem buscar um entendimento materialmente determinado, histórico, contraditório, objetivamente apreensível enquanto "concreto pensado".

A educação é um campo da atividade humana e os profissionais da educação não construíram esse campo segundo ideias próprias, mas em conformidade com condições materiais e objetivas, correspondendo às forças produtivas e relações de produção adequadas aos diferentes modos e organizações da produção, historicamente construídas pelos homens e particularmente consolidadas nas mais diferentes formações sociais.

A discussão da educação a partir de sua articulação com o modo capitalista de produção, na obra marxiana e engelsiana, expressa três movimentos articulados (ou indissociados):

○ $\quad 1^{\circ}$. Possibilita uma profunda crítica do ensino burguês;

- $\quad 2^{\circ}$. Traz a tona como, sob as condições contraditórias desse modo de produção, se dá a educação do proletariado, abrindo perspectivas para uma educação diferenciada, ainda sob a hegemonia burguesa;

○ $\quad 3^{\circ}$. Contraditoriamente, a crítica do ensino burguês e o desvelamento da educação realizada para o proletariado, avançaram em colocar na pauta de lutas do movimento comunista as premissas gerais da educação do futuro; não como utopia, mas como projeto estratégico em processo de construção pelo proletariado.

Marx e Engels insistiram, em praticamente todas as obras, quanto a necessária articulação entre trabalho produtivo e formação intelectual, entendendo que esta relação deveria ser aberta a todos os educandos, e não somente aos filhos dos trabalhadores. Não se tratava de um mero ensino técnico, da aprendizagem de um ofício, mas de uma concepção de educação fundada na articulação entre o ensino com o trabalho produtivo pago. A articulação entre trabalho e educação tem sido exaustivamente pesquisada e teoricamente debatida e concordo com a análise de Saviani, como uma rigorosa abordagem marxista expressa, para quem "trabalho e educação são atividades especificamente humanas", no sentido de que "apenas o ser humano trabalha e educa" (SAVIANI, 2007, p. 152). A fonte dessa articulação teórica entre trabalho e educação, está exposta por Marx e Engels, em A Ideologia Alemã, a partir do entendimento do trabalho como um modo de ser do homem, como meio de produzir sua própria existência. Ao buscarem a distinção do homem dos demais animais expressaram que não é a consciência (ou cultura) que distingue os homens dos outros seres, mas o modo de 
produção de seus meios de vida, como já foi anteriormente explicitado.

Expressavam com isso que, diferentemente dos animais, que não mais fazem do que se adaptar à natureza, os homens é que a ajustavam e a transformavam adequando-a às suas necessidades. $\mathrm{O}$ ato de agir sobre a natureza transformando-a em função das necessidades humanas é o que conhecemos pelo nome de trabalho. Podemos, pois, dizer que a essência do homem é o trabalho. Mas o sentido marxista de essência humana não é o da metafísica: como o conjunto das propriedades imutáveis e eternas do homem, como algo dado ao homem, uma dádiva divina ou natural. Ao contrário, a essência humana é usada no sentido de característica fundamental dos homens, sendo esta produzida pelos próprios homens. O que o homem é, o é pelo trabalho. A essência do homem é um feito humano. É um trabalho que se desenvolve, se aprofunda e se complexifica ao longo do tempo: é um processo histórico.

É, portanto, na existência efetiva dos homens, nas contradições de seu movimento real, e não numa essência externa a essa existência, que se descobre o que o homem é: "tal e como os indivíduos manifestam sua vida, assim são. O que são coincide, por conseguinte, com sua produção, tanto com o que produzem como com o modo como produzem" (MARX E ENGELS, [s.d.], pp. 18-19).

Se a existência humana não é garantida pela natureza, não é uma dádiva natural, mas tem de ser produzida pelos próprios homens, sendo, pois, um produto do trabalho, isso significa que o homem não nasce pronto, mas tem que tornar-se homem. Ele forma-se homem. Ele não nasce sabendo produzir-se como homem. Ele necessita aprender a ser homem, precisa aprender a produzir sua própria existência. Portanto, a produção do homem é, ao mesmo tempo, a formação do homem, isto é, um processo educativo. A origem da educação coincide, então, com a origem do homem mesmo.

Mas não é simples definir o conceito marxiano de trabalho, como "trabalho produtivo", pois é uma expressão usada em duas acepções: por um lado, o termo designa todo e qualquer trabalho que tenha por resultado um produto: "Considerando-se o processo inteiro de trabalho do ponto de vista de seu resultado, então aparecem ambos, meio e objeto de trabalho, como meios de produção, e o trabalho mesmo como trabalho produtivo" (MARX, $O$ Capital, t. 2, p. 105). Por outro lado, porém, o termo também é usado para se referir ao trabalho realizado nas condições particulares da produção capitalista. Como o objetivo do capital é a obtenção do lucro, sendo sua lógica a da acumulação desse lucro, o trabalho é tomado como uma mercadoria que é capaz de produzir um valor muito maior do que o que lhe é pago, um valor excedente, uma mais-valia:

\section{A produção capitalista não é apenas produção de mercadoria, é essencialmente produção de mais-valia. O trabalhador produz não para si, mas para o capital. Não basta, portanto, que produza em geral. Ele tem de produzir mais-valia. Apenas é produtivo o trabalhador que produz mais- valia para o capitalista ou serve à autovalorização do capital. (Idem, ibidem)}

Na primeira acepção, o trabalho "diz respeito ao meio geral de reprodução da vida humana" e na segunda "traduz as condições específicas em que o trabalho se realiza sob a égide do capital" (NOGUEIRA, 1990, p. 90). Para Nogueira, quando Marx e Engels falam de "coordenação dos estudos com o trabalho produtivo", empregam o conceito de trabalho em seu sentido geral e não para se referir ao trabalho sob o capitalismo (Idem, ibidem). Seu entendimento está baseado em "duas ordens de razões": por um lado, a união do ensino e do trabalho deveria, no entender de Marx e Engels, corroborar com a derrubada das condições capitalistas de exploração; por outro, a idéia de união do ensino com a produção usa várias expressões para "trabalho produtivo", como "trabalho físico", "trabalho manual", "trabalho fabril", "produção material", e que apontam "para o sentido geral da noção de trabalho" (Idem, p. 91). 
Penso que Marx e Engels não tratavam o trabalho como uma categoria abstrada (como uma idéia que não possui base material), mas o entendiam a partir das condições em que se realizava no modo capitalista de produção. É com essa visão que trataram da união entre educação e trabalho na perspectiva de superação da exploração capitalista e, portanto, como um meio para a formação desalienada e revolucionária dos filhos da classe trabalhadora. Esse argumento, assim, corrobora com o entendimento de que tratavam da educação não como uma abstração, mas em sua relação contraditória com o modo capitalista de produção, como um poderoso instrumento de formação das novas gerações para a ação política transformadora. Marx e Engels efetivamente defenderam a inserção dos educandos na produção material, no contexto e nas condições da produção e não na perspectiva da escola recriar, imitativamente, o mundo da produção. É isso, em linha gerais o que está contido nas "Instruções aos Delegados do Conselho Central Provisório", AIT, 1868, onde Marx recomenda que a instrução das crianças deveria ser iniciada antes dos nove anos, considerando as reais condições de vida dos operários. Como a utilização do trabalho infantil era uma prática usual, pressupunham a articulação do ensino com o trabalho remunerado, com os exercícios corporais e a aprendizagem politécnica. Essa educação deveria incluir formação geral e formação científica necessária à compreensão de todo o processo de produção e, ao mesmo tempo, iniciar as crianças e jovens no manejo das ferramentas dos diversos ramos industriais (MARX E ENGELS, 1983, p. 60). A educação dos jovens deveria ser dada dos 9 aos 18 anos, cobrindo a formação intelectual, corporal e politécnica; sendo as escolas politécnicas mantidas, em parte, com a venda de seus próprios produtos. Defendia-se, pois, que:

Esta combinação do trabalho produtivo pago com a educação mental, os exercícios corporais e a aprendizagem politécnica, elevará a classe operária bem acima do nível das classes burguesa e aristocrática. (Marx, Resolução do Primeiro Congresso da AIT. In: MARX E ENGELS, 1983, p. 60).

A cultura técnica (formação geral e técnica) constituiria a base da autonomia do operariado no processo de produção, com o ensino politécnico preparando o operário para atuar tanto no processo administrativo como, também, no produtivo. Marx e Engels tratavam de um ensino que realizava-se no contexto da produção, no processo social de produção e sob suas formas características, inclusive a do regime de trabalho assalariado. Essa era, para Marx e Engels, uma dimensão importante da luta da classe operária, e que implicava a luta pelo acesso ao saber, à ciência, à cultura técnica. Nogueira destaca que para eles a luta pelo acesso ao saber pelo proletariado era importante, pois estava diretamente relacionada ao controle dos "conhecimentos técnicos necessários à compreensão do processo de produção" e do qual os trabalhadores foram historicamente expropriados (NOGUEIRA, 1990, p. 91). Para Marx e Engels a expropriação dos saberes e conhecimentos técnicos dos trabalhadores deu-se pela crescente introdução da divisão do trabalho na produção, culminando com a separação do trabalho manual e do trabalho intelectual, resultado da separação dos trabalhadores dos instrumentos de trabalho, das matérias-primas e, enfim, dos próprios produtos produzidos. A revolução era para eles o caminho para a superação das condições de vida e exploração do trabalho pelo capital, com a superação da estrutura de classes burguesa e de uma divisão social e técnica do trabalho que separa e aliena o trabalhador dos meios, processos e resultados da produção. No processo revolucionário, portanto, a educação é um importante instrumento para que o trabalhador consiga não apenas ter acesso aos conhecimentos, mas que, a partir deles, possa controlar o processo de produção e reprodução dos conhecimentos científicos e técnicos envolvidos no processo produtivo.

\section{Marx e Engels: fundamentos da proposta pedagógica comunista}

Marx e Engels não fizeram uma exposição sistemática sobre a escola e a educação, 
assunto já enfatizado neste texto. Ao contrário de terem produzido uma "teoria pedagógica", as posições que foram desenvolvendo encontram-se diluídas ao longo de toda a vasta obra que produziram, estando a problemática educacional indissociavelmente articulada às diferentes questões sobre as quais se debruçaram.

Encontramos entre os estudiosos da educação socialista um esforço de organização e sistematização das referências de Marx e Engels a respeito da educação e da escola e que se encontram no conjunto do seu pensamento sobre a economia, a sociedade e a política. A lista de estudos não é grande, nela estando B. Suchodolski, o pedagogo italiano Mário Alighiero Manacorda, o francês Roger Dangeville, Maria Alice Nogueira, para ficar entre os que me lembro no momento. Em linhas gerais, penso que os trabalhos publicados por esses autores possibilitam organizar a contribuição marxiana à educação em três grandes aspectos ou direções:

1. Pela elaboração de uma rigorsa crítica à educação, ao ensino e à qualificação profissional burguesa. Analogamente à crítica da economia política, Marx e Engels também dirigiram ao ensino burguês uma aguda e profunda crítica, desnudando a relação entre a educação e as condições de vida das classes fundamentais da sociedade burguesa;

2. A profunda análise da educação apartir da relação do proletariado com a Ciência, a cultura e a educação. $\mathrm{O}$ tratamento de Marx e Engels dado à problemática da relação do proletariado com a cultura e a ciência, explicitava como entendiam a ciência a serviço do capital, o processo de alienação resultante do processo de trabalho industrial e o aparelhamento burguês da escola, bem como a importância da educação para a formação da consciência;

3. O delineamento pontual e estratégico dos princípios de uma educação comunista e que deveria estar voltada à formação integral do homem - a educação como articuladora do fazer e do pensar - a superação da monotecnia pela politecnia. A concepção educacional marxiana / engelsiana tinha como ponto de partida a crítica da sociedade burguesa, a proclamação da necessária superação dessa mesma sociedade e como ponto de chegada a constituição do reino da liberdade. Com a instauração do comunismo a educação estará a serviço do homem e, rearticulando o trabalho manual e a atividade intelectual, deverá voltar-se plenamente à formação integral do homem.

O terceiro aspecto ou direção acima apontado é o que que mais me chama a atenção: Educação comunista e formação integral do homem. Penso que o pressuposto de Marx e Engels sobre a educação que interessa aos trabalhadores partidários do comunismo encontrase sistematicamente exposto no próprio Manifesto comunista, escrito entre 1847 e 1848, às vésperas de junho 1848 quando Paris viu a primeira revolução proletária. Entre as medidas que o proletariado poderia colocar em prática ao assumir o poder, Marx e Engels assim redigiram o décimo e último item: "Educação pública e gratuita de todas as crianças, abolição do trabalho das crianças nas fábricas, tal como é praticado hoje. Combinação da educação com a produção material etc". (MARX \& Engels, s.d., Volume 1, p. 37)

Como bem explicita Manacorda (1989, p. 296), Marx e Engels não rejeitaram, mas assumiram as conquistas teóricas e práticas da burguesia no campo da educação, tais como: universalidade, laicidade, estatalidade, gratuidade, renovação cultural e primazia do trabalho. Com o trabalho produtivo, a educação deveria possibilitar o acesso aos conhecimentos historicamente produzidos pela humanidade, em seus aspectos filosófico, científico, literário, intelectual, moral, físico, industrial e cívico. Completa o educador italiano que o marxismo, juntamente com uma dura crítica à burguesia pela incapacidade de realizar os seus programas sociais, introduziu uma concepção mais orgânica da união instrução-trabalho, na perspectiva de uma formação total de todos os homens (Idem, ibidem). Em linhas gerais, a concepção 
marxista de educação foi gradativamente se configurando e assumindo os seguintes princípios: eliminação do trabalho das crianças na fábrica; associação entre educação e produção material; educação politécnica que leva à formação do homem omnilateral, abrangendo três aspectos: mental, físico e técnico, adequados à idade das crianças, jovens e adultos; inseparabilidade da educação e da política; e articulação entre o tempo livre e o tempo de trabalho, isto é, o trabalho, o estudo e o lazer.

A concepção de instrução marxiana é delineada de forma explícita e detalhada nas Instruções aos delegados ao I Congresso da Internacional dos Trabalhadores, que se realizou em Genebra em setembro de 1866. Nesse texto, Marx considera como sendo uma tendência da indústria moderna a colaboração de crianças e adolescentes de ambos os sexos na produção, entendendo que esse é um processo legítimo e saudável, desde que aconteça de modo adequado às forças infantis (MARX, 1983, p. 59). Crítico da violenta exploração do trabalho infantil em atividades econômicas no campo e na cidade, notadamente na indústria, Marx recomendou, entretanto, que a partir dos nove anos qualquer criança deveria participar do trabalho produtivo e trabalhar não somente com o cérebro mas também com as mãos. A exploração nociva à saúde de crianças e adolescentes dessa faixa de idade, entretanto, deveria ser severamente proibida por lei. Essa questão tratei de modo mais alongado anteriormente, mas é importante salientar que Marx não está a defender a exploração do trabalho infantil. Seu entendimento é que o trabalho deveria começar desde a infância, articuladamente com o ensino, os exercícios físicos e o tempo livre. Tendo conhecimento da experiência educacional levada à frente por Owen, bem como outros iniciativas educacionais, Marx defendeu a combinação da educação com o trabalho, inclusive por considerá-lo como um fundamental para a existência econômica, social, psicológica e moral do homem, em qualquer idade, pois o homem não nasce pronto e acabado, mas faz-se vai se fazendo homem (vai se humanizando) desde a infância até a velhice.

Defendendo a combinação entre trabalho produtivo e educação, Marx assim precisou a sua concepção de instrução:

Por instrução nós entendemos três coisas:

1. Educação intelectual.

2. Educação corporal, tal como a que se consegue com os exercícios de ginástica e militares.

3. Educação tecnológica, que recolhe os princípios gerais e de caráter científico de todo o processo de produção e, ao mesmo tempo, inicia as crianças e os adolescentes no manejo de ferramentas elementares dos diversos ramos industriais.

A divisão das crianças e adolescentes em três categorias, de nove a dezoito anos, deve corresponder um curso graduado e progressivo para sua educação intelectual, corporal e politécnica. Os gastos com tais escolas politécnicas serão parcialmente cobertos com a venda de seus próprios produtos.

Esta combinação de trabalho produtivo pago com a educação intelectual, os exercícios corporais e a formação politécnica elevará a classe operária acima das classes burguesa e aristocrática (MARX, 1983, p. 60).

Essa proposta foi assumida pela I Internacional dos Trabalhadores e é o primeiro documento oficial do proletariado moderno sobre a educação, o ensino e a instrução profissional. Conforme se apreende da leitura do item nono, do décimo terceiro capítulo de $O$ Capital, onde Marx analisa a legislação industrial inglesa e suas disposições sobre educação, a construção dessa proposta educacional era uma decorrência histórica e lógica do ensino profissional em curso em várias formações sociais capitalistas - na Inglaterra e na França - e claramente expresso na legislação inglesa sobre as fábricas, que prescrevia a instrução obrigatória para a assunção de crianças no trabalho (MARX, 1982, p. 550-575). Considerando 
a legislação fabril como "um produto necessário da indústria moderna", comparável às máquinas automáticas (Idem, p. 551), as observações de Marx sobre higiene e educação não foram na direção de endossar a instrução profissional burguesa, mas em propor a sua superação. O ponto de partida é a necessidade de universalização da instrução primária, que a legislação "tornou indispensável para o emprego de crianças" (Idem, p. 553). Ao lado da obrigatoriedade da instrução primária, tendo em vista que o trabalho das crianças e adolescentes já era ampla e indiscriminadamente usado pelo capital, também foi a legislação fabril que acabou introduzindo uma nova condição para a educação: a unidade entre instrução e trabalho e que deveria ser destinada a todas as crianças.

A educação proposta, longe de orientar uns para uma profissão e outros para outra, deveria se destinar a todas as crianças e jovens, indistintamente, possibilitando tanto o conhecimento da totalidade das ciências, como das capacidades práticas em todas as atividades produtivas. Tomando por referência os escritos de Robert Owen, delineou Marx a sua proposta de instrução enquanto formação integral de homens:

[...] Do sistema fabril, conforme expõe pormenorizadamente Robert Owen, brotou o germe da educação do futuro, que conjugará o trabalho produtivo de todos os meninos além de uma certa idade com o ensino e a ginástica, constituindo-se em método de elevar a produção social e de único meio de produzir seres humanos plenamente desenvolvidos (Idem, p. 554).

Na visão de Marx a união entre instrução e trabalho industrial não tinha por objetivo simplesmente o aumento de produtividade, mas seu principal objetivo deveria ser o de formação omnilateral do homem, uma formação integral que exigia a rejeição quer "de toda reminiscência romântica antiindustrial", quer de toda didática baseada no jogo e em "outras atividades estúpidas", como bem destaca Manacorda (1989, p. 298).

Os fundamentos dessa educação omnilateral e politécnica era uma decorrência da própria transformação da indústria que constantemente revoluciona as bases técnicas da produção e com ela a divisão do trabalho. Articulando o desenvolvimento das forças produtivas com a implementação de transformações nas bases técnicas de produção, cujas dimensões promovem transformações na divisão do trabalho, é que Marx vislumbrou uma educação mais ampla, integral e flexível:

\section{[...] Por meio da maquinaria, dos processos químicos e de outros modos, a indústria moderna transforma continuamente, com a base técnica da produção, as funções dos trabalhadores e as combinações sociais do processo de trabalho. Com isso, revoluciona constantemente a divisão do trabalho dentro da sociedade e lança ininterruptamente massas de capital e massas de trabalhadores de um ramo de produção para outro. Exige, por sua natureza, variação no trabalho, isto é, fluidez das funções, mobilidade do trabalho em todos os sentidos. [...] (MARX, 1982, pp. 557-558)}

Como se constata, portanto, a necessidade de uma educação flexível foi uma decorrência do desenvolvimento da indústria. Foi o colossal desenvolvimento da indústria que determinou a transformação de todo o aparato escolar, até então dominado pela educação familiar, gremial e religiosa. As transformações desencadeadas pela Revolução Industrial e o desenvolvimento teórico do liberalismo foram responsáveis pelas proclamações de pensadores liberais que atribuíam à educação e ao conhecimento a responsabilidade de criar as condições para a igualdade entre todos os cidadãos. É nesse contexto que verificamos a institucionalização e a ampliação do aparato escolar, como é destacado na "Introdução" aos Textos sobre Educação e Ensino, de MARX \& Engels (1983, p. 9).

Como se sabe, a institucionalização e necessidade de ampliação do aparato escolar, porém, levou a educação a depender crescentemente do Estado, sob a justificativa liberal de que esta deveria ser considerada como uma necessidade social, como um direito de todos os 
cidadãos. Com isso delineava-se o desenvolvimento e consolidação de um aparato escolar de dependência estatal. Bem sabemos que historicamente a ampliação dos sistemas escolares de educação deu-se principalmente a partir do final do Século XIX, quase um século depois dos embates da França revolucionária. Considerando o Estado como um aparato a serviço da classe dominante, mais particularmente a serviço da burguesia, os exemplos já disponíveis para Marx possibilitavam vislumbrar que a educação convertia-se em instrumento de dominação ideológica, um meio para que a burguesia se consolidasse como classe hegemônica e, nessa condição, exercesse o poder: "O estado de classe estava intimamente ligado ao ensino de classe. Ainda que não sem tensões, o aparato escolar se convertia em um apêndice da classe dominante. [...]", conforme a "Introdução" aos Textos sobre Educação e Ensino (MARX \& ENGELS, 1983, p. 10).

Marx e Engels não duvidavam que era necessário às instituições públicas se responsabilizarem pela educação. MAS eles repudiavam o controle que o Estado exercia sobre ela, pois era preciso impedir que a burguesia contasse, além dos outros poderes de que já dispunha, de todo o aparato escolar posto a seu serviço. Sobre o assunto são interessantes as observações constantes na "Introdução", sem autoria assumida, à antologia de Marx e Engels Textos sobre Educação e Ensino:

Este é o contexto em que Marx repudia a intervenção do Estado [...]. Sua preocupação parece clara: que a burguesia não conte, além de outros poderes, com o de um aparato escolar posto a seu serviço, diretamente controlado por ela. No entanto, [...] Marx e Engels não colocam em dúvida a função de responsáveis que as instituições públicas têm com respeito à educação. [...]

[...]

A crítica de dependência escolar do Estado não tem somente aspectos negativos. A proposta sugerida é de sistema de gestão não burocrático, com a intervenção direta da população trabalhadora através de seus delegados e num marco de democracia direta, tal como colocam em relevo suas indicações, já assinalados a propósito da Comuna de Paris. [Introdução. In: MARX \& ENGELS, 1983, pp. 10-11].

As posições de Marx e Engels sobre o controle estatal da educação ficam claramente expressas a partir da discussão na Associação Internacional dos Trabalhadores, em uma intervenção em duas reuniões de seu Conselho Geral, em que estava em pauta a discussão acerca das dificuldades relacionadas ao sistema de ensino e se o mesmo deveria ser público ou privado. Da "Exposição nas Seções dos dias 10 e 17 de agosto de 1869 no Conselho Geral da AIT" consta que Marx, analisando o exemplo dos Estados Unidos da América, se posicionou com relação ao controle estatal da educação, bem como ao direcionamento ideológico do conteúdo educacional pelo partido ou por qualquer classe. O texto do posicionamento de Marx é elucidativo e sobremaneira atual sobre o sistema de ensino:

O cidadão Marx afirma que uma dificuldade de índole particular está ligada a esta questão. Por um lado, é necessário modificar as condições sociais para criar um novo sistema de ensino; por outro, falta um sistema de ensino novo para poder modificar as condições atuais. Consequentemente, é necessário partir da situação atual.

O Congresso da AIT colocou a questão se o ensino deve ser estatal ou privado. Por ensino estatal entende-se aquele que está sob o controle do Estado. [...]

O ensino pode ser estatal, sem ficar sob o controle do governo [...]

Sem a menor dúvida, o congresso pode decidir que o ensino seja obrigatório. $[\ldots]$ 
Os proudhonianos afirmam que o ensino gratuito é um absurdo, posto que o Estado deve pagar. É evidente que um ou outro terá de pagar, porém não é necessário que sejam os que menos podem fazê-lo. O ensino superior não deve ser gratuito.

$[\ldots]$

A discussão avançou após a proposta de ratificar a resolução do Congresso de Genebra, que exige a combinação do trabalho intelectual com o físico, os exercícios físicos com a formação politécnica. [...]

[...]

Nas escolas elementares - e, mais ainda, nas superiores - não faz falta autorizar disciplinas que admitem uma interpretação de partido ou classe. Nas escolas só se deve ensinar gramática, ciências naturais... As regras gramaticais não mudam, seja um conservador clerical ou um livre pensador que as ensine. As matérias que admitem conclusões diversas não devem ser ensinadas nas escolas. [...] (MARX. "Exposição nas Seções dos dias 10 e 17 de agosto de 1869 no Conselho Geral da AIT". In: MARX \& ENGELS, 1983, pp. 96-98).

Não há dúvida da recusa de qualquer interferência político-ideológica na escola, seja qual for sua origem. As intervenções de Marx eram no sentido favorável a uma educação que, sendo pública (estatal) e gratuíta, também fosse livre e laica. Essas observações ganham corpo nas reflexões de Marx sobre a Comuna de Paris, no fim da guerra franco-prussiana de 187071 , onde ficam reafirmadas suas posições face às medidas colocadas em prática pelos comunards. As medidas educacionais da Comuna foram detalhadamente registradas e analisadas por Marx no Primeiro Esboço de "A Guerra Civil na França" e a citação do trecho a seguir, apesar de longa, é esclarecedora sobre o assunto.

Naturalmente, a Comuna não teve tempo de reorganizar a educação pública. No entanto, eliminando os fatores religiosos e clericais, tomou a iniciativa de emancipar intelectualmente o povo. Em 28 de abril nomeou uma comissão encarregada de organizar o ensino primário e profissional. Ordenou que todos os instrumentos de trabalho escolar, tais como livros, mapas, papel, etc. sejam administrados gratuitamente pelos professores, que os receberão de suas respectivas alcaidarias. Nenhum professor está autorizado, sob nenhum pretexto, a solicitar de seus alunos o pagamento por estes materiais de trabalho escolar (28 de abril).

Diante dos desastres que se abateram na França durante esta guerra, diante de seu afundamento nacional e de sua ruína financeira, a classe média sabe que não será a classe corrompida daqueles que tratam de converter-se nos amos da França, a que vai trazer bem-estar, mas sim que será, somente, a classe operária, com suas viris aspirações e seu poder.

Sentem que somente a classe operária pode emancipar-se das tiranias dos padres, fazer da ciência um instrumento não de dominação de classe, mas sim uma força popular; fazer dos próprios cientistas não alcoviteiros dos prejuízos de classe parasitas do Estado 'a espera de bons lugares' e aliados do capital, mas sim agentes livres do espírito. A ciência só pode jogar seu verdadeiro papel na República do Trabalho.

Os professores da escola de medicina evadiram-se e a Comuna designou uma comissão tendo em vista fundar universidades livres que já não sejam parasitas de Estado; esta deu aos estudantes que passaram nos exames a possibilidade de praticar independentemente do título de doutor (o título será conferido pela Faculdade).

A comuna não deve ser uma instituição parlamentar mas sim um corpo dinâmico, executivo e legislativo ao mesmo tempo. Os policiais devem estar 
a serviço da Comuna e não serem instrumentos de um Governo central e, como os funcionários de todos os corpos da Administração, serem nomeados e destituídos sempre pela Comuna; todos os funcionários, de maneira igual aos membros da Comuna, devem realizar seu trabalho com salários de operários. Da mesma forma, os juízes devem ser eleitos, destituídos e responsáveis. Em todas as questões da vida social, a iniciativa há de partir da Comuna. Em uma palavra, todas as funções públicas, inclusive as mais estranhas propostas pelo Governo central, devem ser assumidas por agentes da Comuna, e colocados consequentemente sob seu controle.

É absurdo afirmar que as funções centrais - não só as funções do governo do povo, mas também as necessárias para satisfazer os desejos gerais e ordinários do país - não devem estar asseguradas. Estas funções teriam subsistido, porém os próprios funcionários não podiam - como no velho aparato governamental - colocarem-se acima da sociedade real, porque estas funções deviam estar asseguradas por agentes da Comuna e serem executadas, portanto, sob seu efetivo e constante controle.

A função pública deve deixar de ser uma propriedade privada concedida pelo Governo central a seus auxiliares. O exército permanente e a polícia do Estado, instrumentos físicos da opressão, devem ser eliminados. Expropriando todas as igrejas na medida em que sejam proprietários, eliminando o ensino religioso de todas as escolas públicas e introduzindo simultaneamente a gratuidade do ensino, enviando todos os sacerdotes ao sereno retiro da vida privada para viver da esmola dos fiéis, liberando todos os centros escolares da tutela e da tirania do Governo, a força ideológica da repressão deve se romper: a ciência não só tornar-se-á acessível para todos como também livrar-se-á da pressão governamental e dos prejuízos de classe.

Os instrumentos da opressão governamental e da dominação sobre a sociedade se fragmentarão graças a eliminação dos órgãos puramente repressivos, e ali, onde o poder tem funções legítimas a cumprir, estas não serão cumpridas por um organismo situado acima da sociedade, mas por todos os agentes responsáveis desta mesma sociedade (In: MARX \& ENGELS, 1983, p.92-94).

Com o texto de Marx fica reafirmado o caráter que a educação foi assumindo, acompanhando a reorganização dos serviços públicos pela Comuna: pública (estatal), gratuita, popular e voltada ao atendimento de todos; laica e totalmente livre da influência da religião, das classes e do Estado burguês; formativa e pautada exclusivamente no método experimental e científico. Ademais, a educação foi apontada como um importante instrumento de desalienação do proletariado e vista como uma importante ferramenta de formação e, portanto, um instrumento para a consolidação da revolução proletária.

Para fechar estas observações sobre a perspectiva marxisana de educação e ensino, não tendo a menor intenção de esgotar assunto tão vasto e complexo, recorro novamente a Franco Cambi que, não sendo marxista, assim registrou o mérito de Marx e Engels em introduzir propostas revolucionárias na pedagogia contemporânea.

O modelo pedagógico e educativo elaborado [...] por Marx e Engels introduziu na pedagogia contemporânea pelo menos duas propostas que podem ser consideradas revolucionárias: a referência ao trabalho produtivo, que se punha em aberto contraste com toda uma tradição educativa intelectualista e espiritualista, e a afirmação de uma constante relação entre educação e sociedade, que se manifesta tanto como consciência de uma valência ideológica da educação como projeção "científica" de uma "sociedade liberada", também no campo educativo [...] (CAMBI, 1999, p. 485). 
Entendo que o mérito de Marx e Engels pode ser sintetizado por alguns princípios que desvelam o caráter revolucionário de suas propostas. Em primeiro lugar, está a centralidade dialética do trabalho enquanto princípio educativo e que desemboca na proposta de uma educação omnilateral, em oposição à unilateralidade da educação burguesa. Trata-se de uma educação que deve propiciar aos homens um desenvolvimento integral de todas as suas potencialidades. Para tanto, essa educação deve fazer a combinação da educação intelectual com a produção material, da instrução com os exercícios físicos e estes com o trabalho produtivo. Tal medida objetiva a eliminação da diferença entre trabalho manual e trabalho intelectual, entre concepção e execução, de modo a assegurar a todos os homens uma compreensão integral do processo de produção.

Certamente Marx e Engels também defendiam o estabelecimento de relações necessárias entre educação e sociedade, expressa quer na análise do caráter ideológico e utilitário da educação na sociedade burguesa, quer como projeto de construção de uma sociedade igualitária. Nesse sentido, em vista do projeto estratégico dos partidários do comunismo é que se coloca, desde já, a defesa intransigente de uma educação estatal, gratuita, laica, obrigatória e universal para todas as crianças. Como já explicitado anteriormente por Marx, a educação estatal, entretanto, deve prescindir dos mecanismos de controle que hoje, por exemplo, vislumbramos através de políticas educacionais ditatoriais, cujos mandatários estão a representar instituições financeiras expressivas dos interesses capitalistas. Almeja-se com isso assegurar a abolição do monopólio minoritário e classista da cultura, do conhecimento, da literatura, das artes, da filosofia e da ciência.

A transformação da educação com vistas a tais objetivos, implica uma profunda transformação no modo de produzir dos homens; isso só será alcançado quando também ocorrer uma transformação da divisão social do trabalho que, com a abolição da diferença entre trabalho intelectual e trabalho manual, conduza a uma reaproximação entre a ciência e a produção.

\section{Considerações finais}

Embora não seja fácil uma síntese sobre um assunto que tem produzido vasta literatura, e não poucas controvérsias, retomarei os principais aspectos de uma pedagogia marxista que, apesar de já ficarem apontados anteriormente, podem ser sintetizados em alguns grandes traços que ainda guardam profunda e complexa atualidade, quais sejam:

a) A defesa das conquistas do movimento socialista no que diz respeito à educação e que foram sendo incorporadas ao ideário e à legislação burguesa, notadamente dos seguintes aspectos: educação pública (estatal), gratuita, laica, obrigatória e universal para todas as crianças, de modo a assegurar a abolição do monopólio burguês da cultura e do conhecimento.

b) A combinação da educação intelectual com a produção material, ou usando a formulação de Marx, combinação de instrução, ginástica e trabalho produtivo. O objetivo de tal medida é a eliminação da diferença entre trabalho manual e trabalho intelectual, entre concepção e execução, de modo a assegurar a todos os homens uma compreensão integral do processo de produção. As políticas educacionais burguesas dão ênfase à necessidade de que a educação seja a base para a formação do trabalho; mas, contrariamente à proposta marxiana, a divisão entre trabalho intelectual e trabalho manual é reforçada, dentre muitos outros aspectos, através das divisões, obrigações e responsabilidades pelos diversos níveis de ensino.

c) A educação deve propiciar aos homens o desenvolvimento integral de todas as potencialidades humanas. Todas as necessidades do homem devem emergir no processo educacional, tais como a busca pela sobrevivência, o prazer, a criação e o gozo da cultura, a 
participação na vida social, a interação com os outros homens, a autorrealização e a autocriação. Essa profunda transformação dos objetivos educacionais exige, entre outros aspectos, também uma profunda transformação da divisão social do trabalho que, com a abolição da divisão entre trabalho intelectual e trabalho manual, conduza a uma reaproximação da ciência e da produção. Contrariamente, a escola burguesa professa ideais do desenvolvimento integral do homem que podem ser resumidos em educar para o consumo, para a cidadania nos moldes democráticos burgueses, que já estão conhecidos como extremamente autoritários e excludentes.

d) Também as relações no interior da escola precisam se transformar, ou seja, da competição para a cooperação e para o apoio mútuo. Uma tal transformação pressupõe, por sua vez, uma relação biunívoca e mutuamente enriquecedora entre professor e aluno e uma relação mais aberta entre a escola e a sociedade, a partir da ideia de coletividade e igualdade que constituem a base do comunismo. Trata-se, portanto, de uma concepção diametralmente oposta da burguesa e que enfatiza essa relação como forma de inserção do indivíduo, deixando de lado que se trata de uma sociedade marcada pelas diferenças de classes sociais, portanto, de homens.

Penso que, como em outras partes do mundo, também aqui no Brasil a teoria educacional marxista tem alentado debates e gerado várias propostas e práticas pedagógicas. Defendo que a principal sistematização e difusão entre nós ocorre através da pedagogia histórico-crítica. Para Dermeval Saviani, principal elaborador e referência dessa concepção, a educação é indissociável da sociedade e pode servir tanto de instrumento para a manutenção das condições de exploração e subordinação do proletariado pela burguesia, quanto de alavanca para a necessária transformação histórica da sociedade em direção ao socialismo. Sobre o assunto assim escreveu o autor:

Em relação à posição política assumida por nós, é bom lembrar que na pedagogia histórico-crítica a questão da educação é sempre referida ao problema do desenvolvimento social e das classes. A vinculação entre interesses populares e educação é explícita. Os defensores da proposta desejam a transformação da sociedade... (SAVIANI, 1991, p. 87).

A educação, estando referida ao desenvolvimento histórico da sociedade, cumpre uma função fundamentalmente política. Articulando a elaboração marxiana com os ensinamentos de Gramsci, Saviani entende que a principal função política da educação é de socialização do conhecimento.

[...] conclui-se que a importância política da educação reside na sua função de socialização do conhecimento. É, pois, realizando-se na especificidade que lhe é própria que a educação cumpre sua função política. Daí... que ao se dissolver a especificidade da contribuição pedagógica anula-se, em consequência, a sua importância política. (SAVIANI, 1987, p. 92).

[...] a contribuição da escola para a democratização está no cumprimento da função que lhe é própria: a transmissão/assimilação ativa do saber elaborado. Assume-se assim, a importância da escolarização para todos e do desenvolvimento do ser humano total, cujo ponto de partida está em colocar à disposição das camadas populares os conteúdos culturais mais representativos do que de melhor se acumulou, historicamente, do saber universal, requisito necessário para tomarem partido no projeto históricosocial de sua emancipação humana. (LIBÂNEO, 1987, p. 75).

Sendo a escola uma instituição historicamente determinada, como uma construção humana que se articula ao processo de produção das condições materiais de sua existência, como uma dimensão da realidade humana, para além da mera reprodução da sociedade 
burguesa, pode a educação articular-se plenamente na construção da sociedade sem classes (SAVIANI, 1991, p. 105). Nesse sentido, o educador precisa romper com as pedagogias escolares articuladoras dos interesses da burguesia e vincular sua concepção e sua prática a uma perspectiva revolucionária de homem e de mundo. Não se trata simplesmente de aderir a uma concepção científica de mundo e seu poder desvelador da realidade, mas em assumir na teoria e na prática, isto é, na práxis, uma concepção transformadora da vida, do homem e do mundo. ${ }^{4}$

No meu entendimento, como a burguesia se apropria da ciência e de todos os saberes para impulsionar o desenvolvimento das forças produtivas sob seu controle, bem como para reforçar e naturalizar a dominação de classe, nos cabe (como revolucionários) viabilizar aos que vivem do trabalho o acesso e a apropriação dos conteúdos e saberes elaborados pela humanidade, E para além disso devemos possibilitar, de modo amplo, a formação de consciências críticas, a formação para a luta proletária em defesa de seus próprios interesses, particularmente formando e preparando para a luta revolucionária que conduza a uma transformação histórica radical.

Como a transformação histórica está em curso, abrindo uma longa e dolorosa transição, penso que a expansão da rede escolar, ampliando o acesso da massa trabalhadora à escolarização, não decorreu da benevolência da burguesia e de seus agentes de Estado, mas das próprias lutas desencadeadas pelos trabalhadores. Gostaria de perguntar se isso não traduz, para nós, sob as condições da escola num momento de transição do capitalismo, em lutar por uma educação: PÚBLICA (estatal), GRATUÍTA, UNIVERSAL, INTEGRAL - e isto em termos de seu conteúdo (o que ensinar), de sua forma (como ensinar), em sua organização (quem ensina? Quem aprende?), de seu papel social e que pode ser conservadora, reformista ou emancipadora (o homem como sujeito de sua história). Nesses aspectos a contribuição da Pedagogia Histórico-Crítica é fundamental, pois busca responder a essas e outras questões de nosso tempo. ${ }^{5}$

Entretanto a educação escolar que se dá no interior da rede, nesta época de transição, ainda é limitada, posto que instrumentalizada pela burguesia - concordo que não se pode esquecer que o Estado, e suas instituições, constituem aparelho a serviço dos interesses de uma classe, da burguesia, mas que este também é atravessado pelas contradições que inerentes e característica dos diferentes momentos históricos. Por isso, além de ocupar o espaço escolar e buscar direcioná-lo em conformidade com os interesses de classe do proletariado, é preciso criar alternativas de educação para e pelo proletariado organizado! Acho que é isso o que se propõe uma educação revolucionária e, também neste caso, considero que a Pedagogia Histórico-Crítica cumpre exemplarmente esse papel, pois em seus fundamentos defende que a educação seja gestada com ampla participação da comunidade para a qual se destina; que seja uma educação OMNILATERAL (do homem todo, corpo e intelecto); que seja em TEMPO INTEGRAL, com tempo de atividades escolares e extraescolares; aulas + estudos individuais e em grupo; que articule o ENSINO com o TRABALHO, não do trabalho como diletantismo ou brincadeira infantil, mas que este trabalho seja produtivo e possibilite ao aluno entender como se dá a incorporação da ciência e da tecnologia aos instrumentos e processos produtivos; enfim uma educação que sendo CRÍTICA, esteja centrada nos conteúdos científicos, conquistados pela humanidade ao longo de sua história.

De modo sintético, penso que, como educadores comunistas, nos cabe uma tripla tarefa:

$1^{\text {a }}$. primeiramente empreender uma radical e profunda crítica da educação burguesa, mostrando seus mecanismos classistas de funcionamento, desmistificando e desnaturalizando o caráter classista, burguês, realizado na escola;

$2^{a}$. em segundo lugar, organizarmos uma educação crítica aos trabalhadores, uma prática educativa que possibilite aos despossuídos o acesso ao saber historicamente produzido 
pela humanidade, mas numa perspectiva crítica e articuladora do saber historicamente acumulado pela humanidade;

$3^{\mathrm{a}}$. E ainda, uma FORMAÇÃO política para a luta revolucionária (originalmente esta foi formulada para se dar no interior dos Partidos Comunistas e das instituições de luta dos trabalhadores; mas e hoje, onde esta formação poderia se dar?)

Para que essas tarefas possam ser levadas a cabo, entretanto, é preciso que se tenha EDUCADORES formados numa perspectiva a um tempo histórica e crítica (ou marxista). Essa formação não ocorreu nos cursos de formação de professores ou de pedagogia, hegemonizados que são pelas teorias e ideologias articuladoras do pensamento burguês e mantenedoras da ordem que rege o modo capitalista de produção. Por isso mesmo, defenso que precisamos formar quadros que técnica e politicamente estejam preparados para a implementação de uma pedagogia revolucionária, professores e intelectuais que tenham condições de disputar hegemonia com as concepções pedagógicas burguesas.

\section{Referências:}

CAMBI, Franco. História da Pedagogia. São Paulo : Editora da UNESP, 1999.

DUARTE, Newton. (2000a). Vigotski e o Aprender a Aprender: críticas às apropriações neoliberais da teoria vigotskiana. Campinas: Autores Associados.

DUARTE, Newton. (2000b) (org.). Sobre o Construtivismo: contribuições a uma análise crítica. Campinas: Autores Associados.

DUARTE, Newton. (2003). Sociedade do Conhecimento ou Sociedade das Ilusões?. Campinas: Autores Associados.

ENGELS, F.. A Situação da Classe Trabalhadora na Inglaterra. São Paulo : Global, 1986.

LOMBARDI, J. C.; SAVIANI, D.; SANFELICE, J.L.. Capitalismo, Trabalho e Educação. CAMPINAS - SP : Autores Associados, HISTEDBR, 2002.

LOMBARDI, J.C. A educação e a Comuna de Paris: notas sobre a construção da escola pública, laica, gratuita e popular. In: ORSO, P. J.; LERNER, F.; BARSOTTI, P. (Orgs.) A Comuna de Paris de 1871: história e atualidade. São Paulo: Ícone Editora, 2002, p. 65 - 88.

LOMBARDI, J.C. Reflexões sobre educação e ensino na obra de Marx e Engels. Campinas, SP: $\quad$ Tese (livre docência) - Universidade Estadual de Campinas, Faculdade de Educação, [s.n.], 2010.

LOMBARDI, J.C.. Marxismo e História da Educação: algumas reflexões sobre a historiografia educacional brasileira recente. Campinas - SP : UNICAMP, 1993 (Tese de Doutorado).

LOMBARDI, J.C., SAVIANI, Dermeval (orgs.). Marxismo e educação: debates contemporâneos. Campinas, SP : Autores Associados; HISTEDBR, 2005.

MANACORDA, Mario Alighiero. História da Educação: da Antiguidade aos nossos dias. São Paulo : Cortez : Autores Associados, 1989.

MARSIGLIA, Ana Carolina Galvão (org.). Pedagogia histórico-crítica: 30 anos. Campinas, SP : Autores Associados, 2011.

MARX e Engels. A Ideologia Alemã: crítica da filosofia alemã mais recente na pessoa dos seus representantes Feuerbach, B. Bauer e Stirnes, e do socialismo alemão na dos seus diferentes profetas. Volume I e II. Lisboa : Editorial Presença; Brasil : Livraria Martins Fontes. [s.d.] 
MARX, K. "Prefácio". MARX, K.. Contribuição à Crítica da Economia Política. São Paulo : Martins Pontes, 1983 (2a. ed.).

MARX, K.. O Capital: Crítica da Economia Política - Livro 1, Volume 1. São Paulo : DIFEL, 1982 (7a. ed.)

MARX, K.. O Capital: Crítica da Economia Política - Livro 1, Volume 2. São Paulo : DIFEL, 1982 (7a. ed.).

MARX \& ENGELS. Textos sobre educação e ensino. São Paulo: Moraes, 1983. [há uma edição mais recente: MARX e ENGELS. Textos sobre educação e ensino. São Paulo : Centauro, 2004].

NOGUEIRA, Maria Alice. Educação, saber, produção em Marx e Engels. São Paulo : Cortez : Autores Associados, 1990.

SAVIANI, D.. Educação e questões da atualidade. São Paulo : Livros do Tatu : Cortez, 1991

SAVIANI, Dermeval. "Modo de produção e a pedagogia histórico-crítica”. Germinal:

Marxismo e Educação em Debate, Londrina, v. 1, n. 1, p. 110-116, jun. 2009. Acesso

eletrônico pelo seguinte link:

http://www.uel.br/revistas/uel/index.php/germinal/article/view/2649/2303

SAVIANI, Dermeval. Escola e democracia. São Paulo : Cortez : Autores Associados, 1987.

SAVIANI, Dermeval. Trabalho e educação: fundamentos ontológicos e históricos. In: Revista Brasileira de Educação v. 12 n. 34 jan./abr. 2007, p. 152-180.

SUCHODOLSKI, Bogdan. A Pedagogia e as Grandes Correntes Filosóficas. Lisboa Portugal : Livros Horizonte, 1992.

Notas:

${ }^{1} \mathrm{O}$ presente artigo resulta da parte principal da tese de livre-docência defendida na Faculdade de Educação da Unicamp, resultadode pesquisas e escritos que tenho realizado ao longo dos últimos anos. No presente artigo, buscarei articular algumas passagens (e partes) dessa tese, buscando com isso colocar a problemática do marxismo e da educação em relevo. O texto completo da tese encontra-se disponível na Biblioteca Joel Martins biblioteca setorial da Faculdade de Educação da Unicamp, e o arquivo disponível na Biblioteca Digital da Unicamp. O link para acesso ao arquivo digital, em formato PDF, é: http://libdigi.unicamp.br/document/?code $=40672$

${ }^{2}$ Livre docente em Filosofia e História da Educação e docente da Faculdade de Educação da UNICAMP. É coordenador executivo do HISTEDBR. Bolsa de pesquisador pelo CNPq.

${ }^{3} \mathrm{O}$ grupo tem a liderança de Elza Peixoto e Maria de Fátima Rodrigues Pereira.

${ }^{4}$ Não penso em uma luta fechada no âmbito educacional ou escolar, mas que essa se dê articulada às lutas políticas pela transformação revolucionária da sociedade (através do engajamento em movimentos e aparatos políticos táticos - movimentos sociais, sindicatos - e estratégicos - os partidos e frentes políticas de esquerda).

${ }^{5}$ Para uma visão geral sobre a elaboração e aplicação da Pedagogia Histórico-Crítica, recomendo a leitura da coletânea de MARSIGLIA (2011), resultado de um Seminário que teve por objetivo a discussão sobre os 30 anos da Pedagogia Histórico-Crítica. 